\title{
Mia Couto: escrita e racismo — ou "a arrogância de um único saber"...
}

José Paulo Cruz Pereira

Universidade do Algarve

\begin{abstract}
Resumo
Seguimos aqui a distinção estabelecida por Mia Couto entre a escrita como criação literária — um modo de "descoberta da alteridade" - e a escrita como dispositivo técnico e valor cultural que dela nos pode privar. Tomada em sentido metafísico, enquanto representação secundária e exterior do signo - "um significante do significante" —, a escrita é criticamente retomada, por Jacques Derrida, como traço interno à própria linguagem. É também do mesmo ponto de vista crítico que leremos, não apenas Michel de Certeau, em L'Écriture de l'histoire, acerca de uma modernidade colonial marcada pela oposição binária escrita/oralidade, mas também a ideia de Mia Couto de que, se cultural e politicamente dada como fonte de um "único saber", o sentido comum de escrita pode revelar-se como um último reduto do racismo.
\end{abstract}

Palavras-chave: escrita; oralidade; racismo; teologia; signo.

\begin{abstract}
We follow here Mia Couto's distinction between writing as literary creation - a way of "discovering alterity" - and writing as a cultural practice and technical device that may inhibit that discovery. Understood, in its metaphysical sense, as a secondary and an exterior form of sign representation: "a signifier of the signifier"... - writing is also taken by Jacques Derrida, as an internal feature of language itself. Based on the same critical grounds we will read, not only Michel de Certeau, in his L'Écriture de l'histoire, on a certain colonial modernity, marked by the binary opposition writing/orality, but also Mia Couto's own idea that, if culturally and politically imposed as the source of a unique knowledge, the common sense notion of writing will turn out to be a last haven for racism.
\end{abstract}

Keywords: writing; orality; racism; theology; sign.

Recebido em: 05/01/2020

Aprovado em: 27/08/2020

\section{A escrita como notação linear: a foraclusão do Outro...}

Há nos "textos de intervenção" de Mia Couto dois sentidos bastante diferentes para a palavra "escrita". Por um lado, ela refere-se ao processo e ao ato de criação literária. Por outro, a uma operação escriturária que, própria de uma certa lógica cultural urbana, tenderia a eleger o escrito como repositório de um saber único e, nesse sentido, a reprimir ou a despromover os 
preceitos do mundo da oralidade. Poderíamos encontrá-la em passagens de E se Obama fosse Africano? e outras interinvenções. Por exemplo, em "Quebrar armadilhas":

Uma terceira armadilha é pensar que a sabedoria tem residência exclusiva no universo da escrita. É olhar a oralidade como um sinal de menoridade. [...] O culto de uma sabedoria livresca pode contrariar o propósito da cultura e do livro, que é o da descoberta da alteridade (COUTO, 2009b, p. 107).

Com feito, este conceito de "escrita" — como "arquivo" ou repositório do saber politicamente sancionado, com todos os efeitos de poder daí decorrentes... — opõe-se, ele mesmo, à descoberta da alteridade. Fá-lo na medida em que traz consigo uma redução dos saberes, uma menorização das etnofilosofias respeitantes às culturas pertencentes ao mundo da oralidade, ou regidas pela sua lógica. O que levará Mia Couto a observar: "A mais importante linha divisória em Moçambique não é tanto a fronteira que separa analfabetos e alfabetizados, mas a fronteira entre a lógica da escrita e a lógica da oralidade" (COUTO, 2009b, p. 108).

Essa "lógica da escrita" estabeleceu-se no universo urbano: "em Moçambique, como no resto do mundo, a lógica da escrita instalou-se com absoluta hegemonia" (COUTO, 2009b, p. 108). Dela se distanciaria a lógica do mundo rural: "a absoluta maioria dos 20 milhões de moçambicanos vive e funciona num tipo de racionalidade que tem pouco a ver com o universo urbano" (COUTO, 2009b, p. 108). O que supõe, neste hiato potencialmente conflitual entre racionalidades distintas, um problema ético e político no plano da heterogeneidade cultural do país. Por um lado, porque seria, então, necessário dar voz a essa "absoluta maioria" de moçambicanos, assim remetida ao silêncio. "O idioma português é [...] um território cultural inventado por negros urbanizados, mestiços, indianos e brancos. [...] Os outros moçambicanos correm o risco de ficarem de fora, afastados dos processos de decisão, excluídos da modernidade" (COUTO, 2009d, 187).

Por outro lado, porque não menos necessário se faria, então, interrogar os pressupostos de uma lógica da escrita que, hegemonicamente instalada no universo urbano, se interpõe à possibilidade de escuta daquela "absoluta maioria" de moçambicanos. A "lógica da escrita" representa uma série de ameaças:

Nesses casos, pressupostos filosóficos do mundo rural correm o risco de ser excluídos e extintos. [...] A concepção relacional da identidade, inscrita no provérbio: "eu sou os outros"; a ideia de que a felicidade se alcança não por domínio, mas por harmonia; a ideia de um tempo circular, o sentimento de gerir o mundo em diálogo com os mortos [...] (COUTO, 2009b, p. 108).

Tais seriam alguns dos exemplos arrolados, dos quais essa lógica urbana da escrita destoa. O desfasamento dessa lógica da escrita, em relação à lógica da oralidade, tornar- 
se-ia patente, por exemplo, a propósito do conceito de leitura. Habitualmente associado às preocupações formativas expressas, no sistema educativo, a respeito das novas gerações, esse conceito resultaria, afinal, do lado daquela lógica da escrita, de um certo senso comum: "Falamos em ler e pensamos apenas nos livros, nos textos escritos. O senso comum diz que lemos apenas palavras. Mas a ideia de leitura aplica-se a um universo vasto. [...] Tudo pode ser página" (COUTO, 2009b, p. 109).

Isso exigiria que se considerassem, igualmente, as práticas e os preceitos das culturas do mundo rural como parâmetro: "nós lemos emoções nos rostos, lemos os sinais climáticos nas nuvens, lemos o chão, lemos o Mundo, lemos a vida" (COUTO, 2009b, p. 109). Ou ainda: "Sou biólogo e viajo muito pela savana do meu país. Nessas regiões encontro gente que não sabe ler livros. Mas que sabe ler o seu mundo. Nesse universo de outros saberes, sou eu o analfabeto" (COUTO, 2009a, p. 17).

Com efeito: "Não sei ler os sinais da terra, das árvores e dos bichos. Não sei ler nuvens, nem o prenúncio das chuvas. Não sei falar com os mortos, perdi o contacto com os antepassados que nos concedem o sentido da eternidade" (COUTO, 2009a, p. 17).

Portanto: "Vou aprendendo sensibilidades que me ajudam a sair de mim e a afastarme das minhas certezas. Nesse território, eu não tenho apenas sonhos. Eu sou sonhável" (COUTO, 2009a, p. 17).

O que supõe que, a cada viagem, se retomasse, então, uma espécie de infância de si - no que ela supõe, em Mia Couto, quer de uma espécie de "sonho acordado" (2019, p. 104), quer de uma plasticidade ficcional e de uma intuição poética (COUTO, 2009a, p. 14) necessárias à sua criação literária. O que sublinharia, no entanto, o facto de que "saber ler" — do ponto de vista daquela "lógica urbana da escrita" - representaria, sobretudo, uma operação de conversão de letras, em sons e sentidos. Restringir-se-ia, em suma, a uma forma de decifração: a uma decodificação de carateres, grafados ou impressos. A um saber técnico, portanto: uma aplicação dos códigos ortográficos, gramaticais e lexicográficos a que, numa palavra, essa prática instrumental da escrita remeteria. Seria então necessário chegar ao mundo rural - ou por ele passar... - para se ter uma visão mais abrangente da complexidade das operações semiológicas envolvidas pela leitura? Não - a não ser para contrariar esse sentido estrito de "leitura" que, marcado pelo senso comum do universo letrado, é o que grassa pelas cidades... O que aí se expandiria seria, assim, uma espécie de assimbolia generalizada: “[Tudo...] Depende apenas da intenção de descoberta do nosso olhar. Queixamo-nos de que as pessoas não lêem livros. Mas o déficit de leitura é muito mais geral. Não sabemos ler o mundo, não lemos os outros" (COUTO, 2009b, p. 109).

Ora, o ato de leitura deveria, também ele, abrir para a produção semiológica do seu objeto. E, por conseguinte, para uma apropriação ativa das posições que, nele enunciadas, haveriam de inspirar, ao leitor, a assunção da sua posição enunciativa num texto a produzir(-se). A leitura 
suporia, pois, uma espécie de deslocadora e dinâmica indução, de performativo embraiamento: "Vale a pena ler livros ou ler a Vida quando o acto de ler nos converte num sujeito de uma narrativa, isto é, quando nos tornamos personagens. Mais do que saber ler, será que sabemos, ainda hoje, contar histórias?" (COUTO, 2009b, p. 109).

À "lógica [urbana] da escrita" faltaria, pois, a circularidade pela qual, no mundo rural, do escutador de uma história se esperaria a sua reversão: em seu (co/re)produtor:

Os contadores de histórias do meu país têm de proceder a um ritual quando terminam a narração. Têm de "fechar" a história. [...] O que acontece quando não se fecha a história? A multidão que assiste fica doente, contaminada por uma enfermidade que se chama doença de sonhar (COUTO, 2009c, p. 125).

A não ser que se "feche" a história, usando-se de uma fórmula ritual — "Volta para casa de Guambe e Dzavane" - ela tenderá a continuar-se, por entre a assistência. E em Mia Couto, o "sonho" é um outro nome do processo da invenção literária (COUTO, 2009a, p. 14). Ora, um dos traços que releva daquela "lógica urbana da escrita" reside na sua conceção do tempo. A historicidade que lhe diz respeito é marcada pela ideia de um tempo que, linear e irreversível, se afasta do tempo circular da lógica rural da oralidade (mais afeito à repetição cíclica das estações). Essa noção de tempo teria tido origem, no que se refere ao Ocidente, nos modelos cristãos da época helenística. Precisamente aí, onde se impôs a ideia teológica de uma vida concebida como uma prova de obstáculos a superar. Diz-nos Michel Foucault, em L'herméneutique du sujet, ao abordar as transformações históricas das antigas práticas do "cuidado de si": "On avait vu la généralisation de cette idée de l'epimeleia heautou [...] dans cette culture de soi de l'époque hellénistique et impériale $[\ldots]$ on trouve l'idée de l'éducation $[\ldots]$ : c'est la vie toute entière qui doit être éducation de l'individu" (FOUCAULT, 2001a, p. 421).

Essa concepção da "vida como educação" assentava na projeção da heterogeneidade dos acontecimentos, com que a vida se defronta, sobre um fundo de intervenção divina. Entendida como decorrente dos desígnios antecipados de um Deus provedor da sua formação, ela era dirigida, sobretudo, aos homens capazes de exercer, sobre si próprios, as modificações aconselhadas pela experiência:

La pratique de soi qui doit se dérouler [...] jusqu'à la fin de la vie, cette pratique de soi s'inscrit à l'intérieur d'un schéma providentiel qui fait que Dieu répond en quelque sorte à l'avance, organise pour cette formation de soi-même, [...] un monde tel qu'il a pour l'homme valeur formatrice (FOUCAULT, 2001a, p. 421).

Giorgio Agamben chama-nos, no seu Enfance et histoire, igualmente a atenção para esta espécie de genealogia. A partir da sua concepção cristã, esse tempo não se degradará sem a interferência, quer da revolução industrial, quer da secularização decorrente do 
desenvolvimento das ciências da natureza. Diz-nos ele, na seção "Temps et histoire — critique de l'instant et du continu":

L'expérience chrétienne du temps [...] se déroule de manière irréversible, de sa création à sa fin - avec pour référence central l'incarnation du Christ, qui caractérise ce déroulement comme progression de la chute initiale à la rédemption finale (AGAMBEN, 2000, p. 117).

De fato: "o tempo contínuo e quantificado [dos gregos antigos] não foi abolido, mas simplesmente deslocado do movimento dos astros para a experiência interior" (AGAMBEN, 2000, p. 118). Se, portanto, é possível dizer que:

L'histoire de l'humanité apparaît comme une histoire du salut, c'est-à-dire de la réalisation progressive d'une rédemption, dont le fondement est en Dieu. [... qui] coupe résolument le temps du mouvement naturel des astres, pour en faire un phénomène essentiellement humain et intérieur (AGAMBEN, 2000, p. 117).

Só a partir da Revolução Industrial se verifica que "a concepção moderna do tempo é uma laicização do tempo cristão retilíneo e irreversível; mas ela elimina toda a ideia de fim e não conserva senão o sentido de um processo estruturado segundo o antes e o depois" (AGAMBEN, 2000, p. 119, tradução nossa).

Até quando, no entanto, terá perdurado aquela anterior concepção providencial do tempo? Talvez Karl Löwith, em $O$ sentido da história, nos pudesse sugerir já uma resposta, quando observava: "com esta secularização da fé cristã, [...] com esta concepção do espírito, Hegel julgava-se leal ao génio do cristianismo realizando o reino de Deus na terra" (LÖWITH, 1990, p. 64). E Theodor Adorno, em Dialectique négative, o pudesse confirmar:

L'exigence philosophique de descendre jusqu'au détail [...] constituait déjà un des aspects de Hegel. Seulement [...] sa manière de plonger dans le détail met au jour, comme si c'était convenu d'avance, cet esprit qui était posé dès le début comme totalité et comme Absolu (ADORNO, 2001, p. 292, grifo nosso).

Que pensar, no entanto — hoje — dessa "totalidade" e desse Absoluto?

\section{Michel Foucault: poder/saber — ou os saberes subjugados...}

Num texto famoso - respeitante à primeira de duas conferências intituladas "Two lectures" e publicadas em Power/knowledge: selected interviews and other writings - em que nos dá conta da sua percepção quanto às mutações entretanto ocorridas, sobretudo a partir dos anos 1960, Michel Foucault fala-nos do que, em outros autores, haveria de surgir associado ao que se vem designando de "pós-moderno". Que nos diz ele? 
I would say, then, that what has emerged in the course of the last ten or fifteen years is a sense of the increasing vulnerability to criticism of things, institutions, practices, discourses. A certain fragility has been discovered in the very bedrock of existence [...] (FOUCAULT, 1980, p. 80)

Essa vulnerabilidade punha a descoberto "algo que talvez não fosse inicialmente previsto, algo que se poderia descrever como o efeito inibidor das teorias globais, totalitárias" (FOUCAULT, 1980, p. 80). O marxismo e a psicanálise seriam dois exemplos, para além do existencialismo sartriano: "Em ambos os casos a tentativa de os pensar em termos de uma totalidade provou ser um obstáculo à investigação" (FOUCAULT, 1980, p. 81). Essa nova crítica fazia-se sentir através das releituras de Marcuse e Willelm Reich, Lacan ou Deleuze. E referindo-se às linhas do seu próprio trabalho, diria Foucault:

They were merely lines laid down for you to pursue or to divert elsewhere, for me to extend upon or re-design as the case might be. They are, in the final analysis, just fragments, and it is up to you or me to see what we can make of them (FOUCAULT, 1980, p. 78-79).

Também ele se afeiçoava, nesse sentido, aos modos da nova crítica das práticas sociais, das instituições e discursos: "eu esbocei uma história genealógica da teoria e do conhecimento da anomalia e das várias técnicas com ela relacionadas. Nada disto mais faz que marcar o tempo" (FOUCAULT, 1980, p. 79, tradução nossa). E é neste contexto que nos é, então, apontada a segunda caraterística desses tempos. Ela será aqui a que mais nos importará salientar:

It also seems to me that over and above, and arising out of this thematic [of not being "theory, but life that matters, not knowledge but reality; not books but money, etc."...] there is something else to which we are witness, and we might describe as an insurrection of subjugated knowledges (FOUCAULT, 1980, p. 81, grifos do autor).

E acrescenta: "By subjugated knowledges I mean two things: on the one hand, I am referring to the historical contents that have been buried and disguised in a functionalist coherence or formal systematisation" (FOUCAULT, 1980, p. 81).

Assim, essa insurreição de tais saberes subjugados teria, sobretudo, sido desencadeada pela "emergência imediata de conteúdos históricos" (FOUCAULT, 1980, p. 81). Em que termos? Por quê? "[...] this is simply because only the historical contents allow us to rediscover the ruptural effects of conflict and struggle that the order imposed by a functionalist or systematising thought is designed to mask" (FOUCAULT,1980, p. 82).

A história devia, portanto, participar do seu próprio desmentido. Mas a contraargumentação crítica, destinada a recolocar esses conteúdos históricos em cena, para assim os 
resgatar da sua ocultação sob o efeito de máscara exercido pelas "teorias totalitárias", deveria fazer intervir um segundo elemento:

Subjugated knowledges are thus those blocs of historical knowledge which were present but disguised within the body of functionalist and systematising theory and which criticism - which obviously draws upon scholarship - has been able to reveal (FOUCAULT, 1980, p. 82, grifo nosso).

Tratar-se-ia da "investigação". Mas aqui num sentido já muito diferente daquele anteriormente patente, nas grandes sistematizações teóricas pelas quais se visara encobri-los, dissimulá-los ou apagá-los, até recalcá-los. Tais saberes subjugados emergiriam, então, como:

Naive knowledges [...] a particular, local, regional knowledge, a differential knowledge incapable of unanimity, [... an] association between buried knowledges of erudition and those disqualified from the hierarchy of knowledges and sciences (FOUCAULT, 1980, p. 82).

Em certa medida, o que teria acontecido na esfera do saber teria, portanto, sido semelhante ao que acontecera, também, na esfera da cultura — onde as demarcações tradicionais entre low e high deixariam, também por volta dos anos 1960, de funcionar. O discurso crítico munia-se de formas de erudição entretanto recusadas, associadas a tais "saberes ingênuos [naive knowledges] situados abaixo na hierarquia, abaixo do nível requerido de cognição ou cientificidade" (FOUCAULT, 1980, p. 82, tradução nossa). De que tipo de "conteúdos históricos imediatamente emergentes" poderíamos estar aqui a falar? Diz-nos Foucault que, "nos dois casos", esses saberes se ligam sempre a "um conhecimento histórico de lutas" (FOUCAULT, 1980, p. 83, tradução nossa): em ambas as formas de saber - a erudita e a naïf... - se encontrava "a memória de encontros hostis que se mantiveram até hoje à margem do conhecimento" (FOUCAULT, 1980, p. 83, tradução nossa). Daí: "What emerges out of this is something one might call a genealogy, or rather a multiplicity of genealogical researches, a painstaking rediscovery of struggles together with the rude memory of their conflicts" (FOUCAULT, 1980, p. 83).

Boa parte do discurso crítico assumiria, assim, dos meados do século XX em diante, a natureza de uma "crítica genealógica":

And these genealogies [...] were not possible and could not even be attempted except on one condition, namely that the tyranny of globalising discourses with their hierarchy and all their privileges of a theoretical avant-garde was eliminated (FOUCAULT, 1980, p. 83). 
Em que consistiria, no entanto, uma "genealogia"? O seu conceito provém de Friedrich Nietzsche:

Or, si le généalogiste prend soin d'écouter l'histoire plutôt que de ajouter foi à la métaphysique, qu'apprend-il? Que derrière les choses il y a «tout autre chose » : non point leur secret essentiel et sans date, mais le secret qu'elles sont sans essence, ou que leur essence fut construite pièce à pièce à partir de figures qui étaient étranges (FOUCAULT, 2001b, p. 1006).

Assim, "o que se encontra, no começo histórico das coisas, não é a identidade ainda preservada da sua origem - mas a discordância das coisas, a sua disparidade" (FOUCAULT, 2001b, p. 1006, tradução nossa). Uma genealogia orientada pela busca da origem "não é senão uma invenção das classes dirigentes” (FOUCAULT, 2001b, p. 1006, tradução nossa): “o genealogista tem necessidade da história para conjurar a quimera da origem" (FOUCAULT, 2001, p. 1008, tradução nossa). Para Nietzsche,

Suivre la filière complexe de la provenance, c'est au contraire maintenir ce qui s'est passé dans la dispersion qui lui est propre : [...] c'est découvrir qu'à la racine de ce que nous connaissons et de ce que nous sommes il n'y a point la vérité et l'être, mais l'extériorité et l'accident (FOUCAULT, 2001b, p. 1009).

E contra o apagamento historiográfico da posição do historiador - naquilo que Nietzsche chamaria de "história antiquária" — a história efetiva:

Elle ne craint pas d'être un savoir perspectif. [...] Le sens historique, tel que Nietzsche l'entend, se sait perspective, et ne se refuse pas le système de sa propre injustice. [...] La wirkliche Historie effectue, à la vertical du lieu où elle se tient, la généalogie de l'histoire (FOUCAULT, 2001b, p. 1018).

Que nos deveria conduzir à questão da possibilidade de conceber este mesmo tipo de genealogia, quer a respeito da escrita quer dos conceitos que, envolvidos no seu funcionamento - entendida ela nos termos de Mia Couto... - nos permitiriam compreendê-la como potencialmente adversa a essa "descoberta do Outro" que devia, no entanto, ser a vocação da literatura e do livro? Uma resposta poderia vir-nos, aqui, de Homi K. Bhabha. Mas também de Jacques Derrida e, ainda, de Michel de Certeau. E de Bhabha: “[...] a range of contemporary critical theories suggest that it is from those who have suffered the sentence of history subjugation, domination, diaspora, displacement - that we learn our most enduring lessons for living and thinking" (BHABHA, 1994, p. 172).

Os pressupostos da teoria pós-colonial incorporariam a afinidade pressuposta por essa aprendizagem — de que "a experiência afetiva da marginalidade social transforma as nossas 
estratégias" (BHABHA, 1994, p. 173, tradução nossa)... — quando ela se propõe resistir a formas holísticas de compreensão e explicação dos processos de transformação social e cultural:

The postcolonial perspective resists the attempt at the holistic forms of social explanation. It forces a recognition of the more complex cultural and political boundaries that exist on the cusp of these often opposed political spheres [the First and the Third World ones] (BHABHA, 1994, p. 173).

Daí o abandono de "as tradições da sociologia do subdesenvolvimento e do terceiro mundo ou da teoria da [sua] 'dependência"” do primeiro mundo, para começar por reconhecer, fora desses alinhamentos globais e sistematizantes, aquilo a que chama uma "localização híbrida do valor cultural" (BHABHA, 1994, p. 173, tradução nossa), nas dimensões transnacional e tradutória das linhas de fratura que atravessam os espaços liminares em jogo, no interior dessas sociedades e culturas.

My growing conviction has been that the encounters and negotiations of differential meanings and values within the colonial textuality [...] have anticipated avant la lettre, many of the problematics of signification and judgement that have become current in contemporary theory (BHABHA, 1994, p. 173).

Os exemplos que nos traz, de tais problemáticas, enumeravam-se assim: "aporia, ambivalência, indeterminação, a questão da clausura discursiva, a ameaça da agência, o estatuto da intencionalidade, o desafio a conceitos totalizadores" (BHABHA, 1994, p. 173, grifo nosso, tradução nossa). Não estaríamos já diante de um repertório de conceitos-pivot que, recorrentes naquela crítica genealógica, nos sugerem, afinal, o questionamento daqueles sistemas globais e "totalitários"?

In general terms, there is a colonial contramodernity at work in the eighteenth- and nineteenth-century matrices of Western modernity that, if acknowledged, would question the historicism that analogically links, in a linear narrative, late capitalism and the fragmentary, simulacral, pastiche symptoms of postmodernity (BHABHA, 1994, p. 173).

O que a narrativa linear desse historicismo não chegaria a explicar seriam aquelas "tradições de contingência cultural e de textual indeterminação ([encaradas] como forças sociais) geradas pela tentativa de produzir um sujeito colonial ou pós-colonial 'iluminado"” (BHABHA, 1967, 173, tradução nossa). E por quê? O texto de H. Bhabha extrai a sua epígrafe de "My chanches / mes chances. A rendezvous with some epicurean stereophonies", de Jacques Derrida: "Para alguns de nós, o princípio de indeterminação é o que torna a liberdade consciente sondável” (BHABHA, 1967, p. 171, tradução nossa). Ora, aquelas “contingências culturais e de 
indeterminação textual" são precisamente um dos temas de fundo de Derrida, que encontrava já, em Epicuro (e Lucrécio), a ideia de um “desvio suplementar":

I will quickly say in which direction my present remarks are inclined: it is not to the indivisibility but to the divisibility or internal difference of the so-called ultimate element (stoikheion, trait, letter, seminal mark) that we are led by the phenomenon of chance, as well as by that of literary fiction, to say nothing of what I call writing or the trace in general (DERRIDA, 2007, 354).

O pressuposto de Bhabha é, portanto, o da deslocação interruptiva de qualquer linearidade historicista pela mimicry (pós-)colonial. Ou pelo que nela haveria da reescrita, ou de recontextualização da marca ou rastro em geral. Posto que estes se opõem — como se vê, em De la grammatologie - a um conceito metafísico ou logocêntrico de escrita que a dava exclusivamente "pensada do lado da cultura, da técnica e do artifício, [como a] astúcia de um ser encarnado por acidente ou de uma criatura finita" (DERRIDA, 1967a, p. 26).

Ainsi, à l'intérieur de cette époque [de l'histoire de la métaphysique], la lecture et l'écriture, la production ou l'interprétation des signes, le texte en général, comme tissu de signes, se laissent confiner dans la secondarité. Les précèdent une vérité ou un sens déjà constitués par et dans l'élément du logos (DERRIDA, 1967a, p. 26).

Com efeito, esta concepção metafísica de escrita haveria de questionar-se, desconstrutivamente, a partir do que nela relevaria já do rastro. Mas de um "rastro" aqui entendido — no plano do significante quer sonoro, quer gráfico... - como portador de uma irredutível e deslocadora exterioridade a si. Um rastro, assim, obliterador de qualquer pressuposta presença plena, de qualquer significado transcendental ou de verdade a priori. Rastro rasurante, portanto, de qualquer nome "próprio" (cuja "propriedade" se entendesse na sua adequação à coisa nomeada). De fato, continuaria Jacques Derrida: "a época do logos rebaixa portanto a escrita pensada como mediação de mediação e queda na exterioridade do sentido" (1967a, p. 24, tradução nossa). E esse rebaixamento revela-se solidário de um conceito de "signo" a interrogar: "Il s'agit d'abord de mettre en évidence la solidarité systématique et historique de concepts et de gestes de pensée qu'on croit souvent pouvoir séparer innocemment. Le signe et la divinité ont le même lieu et le même temps de naissance (DERRIDA, 1967a, p. 25, grifo nosso).

Pois, como insistirá: “a época do signo é essencialmente teológica” (DERRIDA, 1967, p. 25, tradução nossa). Por quê? Porque à diferença tradicional entre significado e significante - que o signo supõe... - nos não seria possível retê-la sem que, ao mesmo tempo, conservássemos a distinção platônica entre o inteligível e o sensível (DERRIDA, 1967a, p. 25). Esse signo representaria, assim, um estranho compromisso: entre um certo Presente (ou uma certa eternidade da Origem) — na instância do logos ou do significado transcendental... 
- e uma certa finitude da sua encarnação material, da sua queda no significante. Em que nos poderia isto ajudar a pensar aquela escrita que, em Mia Couto, se nos dá como potencialmente contrária à "descoberta do outro"?

\section{A escrita como "obliteração do próprio": a "descoberta do outro"...}

A explicitação dessa espécie de constituição assimétrica - e de interpretação teológica do signo, em cuja pretensa unidade se acolheria uma relação binária na qual o significante será sempre a face decaída, marcada - ganha, contudo, um especial relevo, no Ocidente, a partir da expansão do criacionismo e do infinitismo cristãos, na sua apropriação da conceptualidade grega:

La différence entre signifié et signifiant appartient de manière profonde et implicite à la totalité de la grande époque couverte par l'histoire de la métaphysique, de manière plus explicite et plus systématiquement articulée à l'époque plus étroite du créationnisme et de l'infinitisme chrétiens lorsqu'ils s'approprient les ressources de la conceptualité grecque (DERRIDA, 1967a, p. 24, grifo nosso).

Não seria, portanto, apenas um certo conceito de tempo - linear e irreversível, te(le)ologicamente orientado por uma certa ideia de desfecho ou de revelação, de redenção ou de salvação... - o que nesse momento historicamente se explicita. Seria, também, esta perturbadora cumplicidade: entre o "significado" (enquanto anterior e exterior à sua encarnação material) e a presença da divindade - no espírito ou na alma, e/ou na essência dos seres e das coisas... - antes que algum significante lhe desse corpo, inscrevendo-o, ao mesmo tempo, numa irredutível exteriorização a si. Hoje ocorreria, para Derrida:

Par une nécessité qui se laisse à peine percevoir, tout se passe comme si, [...] cessant de désigner la pellicule extérieure, le double inconsistant d'un signifiant majeur, le signifiant du signifiant, le concept d'écriture commençait à déborder l'extension du langage (DERRIDA, 1967a, p. 16, grifos do autor).

Tudo se passaria, assim, como se a palavra escrita tendesse a perder a sua anterior e exclusiva ancoragem num sentido primeiro e literal - referente à sua secundariedade gráfica em relação ao signo da fala (quer ao significado ou ao logos que o precede, quer ao significante sonoro em que ele se exprime), aqui sublinhada pela expressão “película exterior”... E o fizesse para passar a referir-se a uma certa relação significante que, já inscrita na linguagem, assim tenderia a retirar, ao significado, a sua longamente inquestionada prioridade e primazia. "Non que le mot « écriture » cesse de désigner le signifiant du signifiant, mais il apparaît [maintenant] dans une étrange lumière que "signifiant du signifiant» cesse de définir le redoublement accidentel et la secondarité déchue" (DERRIDA, 1967a, p. 16). 
O sentido da expressão "significante do significante" passaria, assim, a supor, no plano da linguagem, uma certa obliteração da verdade como adequação, uma certa rasura do "nome próprio" - não no sentido que lhe é comum, nas gramáticas (e que o diferencia dos chamados "nomes comuns"), mas antes.. - quanto à maior ou menor "propriedade" da sua nomeação. Por isso:

L'avènement de l'écriture est l'avènement du jeu; le jeu aujourd'hui se rend à luimême, effaçant la limite depuis laquelle on a cru pouvoir régler la circulation des signes, entraînant avec soi tous les signifiés rassurants, réduisant toutes les places-fortes, tous les abris du hors-jeu qui surveillaient le champ du langage (DERRIDA, 1967a, p. 16).

Esse apagamento do limite entre signo e coisa, no jogo da linguagem que a afeta no seu campo, não seria sem consequências, para o questionamento desta demarcação entre uma certa "lógica urbana da escrita" e uma "lógica rural da oralidade", de que estamos a tratar ... Pois, como observará Jaques Derrida:

Si l'on cesse d'entendre l'écriture en son sens étroit de notation linéaire et phonétique, on doit pouvoir dire que toute société capable de produire, c'est-à-dire d'oblitérer ses noms propres et de jouer de la différence classificatoire, pratique l'écriture en général (1967b, p. 161).

Com efeito, essa "escrita em geral" - que não é apenas coextensiva à linguagem, mas que também a excede ou transborda, no sentido em que nada do que, de exterior, entra no seu campo, se pode, afinal, conceber sem ela... - no que ao funcionamento do "significante do significante" diz respeito, também ela supõe que "quando na consciência o nome se diz próprio, ele classifica-se e oblitera-se já, ao denominar-se. Já não é mais que um nome que se diz próprio" (DERRIDA, 1967b, p. 160-161, grifos do autor). O que implicaria, do ponto de vista da diferenciação de que aqui nos temos ocupado, que: “À l'expression de « société sans écriture » ne répondrait donc aucune réalité ni aucun concept. Cette expression relève de l'onirisme ethnocentrique, abusant du concept vulgaire, c'est-à-dire ethnocentrique, de l'écriture" (DERRIDA, 1967b, p. 161).

A atitude de menosprezo da "escrita" - pela sua aparente secundariedade e exterioridade à presença do sujeito e da voz... "Escrita" concebida como uma espécie de reflexo representativo, marcado pela sua natureza de "película exterior", de "significante do significante" do discurso a que se dá voz... - releva, paradoxalmente, do mesmo etnocentrismo capaz de estabelecer esta oposição binária entre as sociedades ditas "sem escrita” e aquelas que, já no pensamento moderno (embora) colonial, se davam como superiores, portadoras de história e de civilização, de progresso científico e superioridade tecnológica, ou de um presumido refinamento ético e moral. Mesmo a Lévi-Strauss - cujas implicações etnocêntricas remontariam à influência de 
Rousseau (DERRIDA, 1967b, p. 197-202) — ocorreriam afirmações como esta: “Après qu'on a éliminé tous les critères proposés pour distinguer la barbarie de la civilisation, on aimerait au moins retenir celui-là: peuples avec ou sans écriture, [...]” (DERRIDA, 1967b, p. 187).

Quais seriam, então, as diferenças entre uns e outros?

[...] les uns capables de cumuler les acquisitions anciennes et progressant de plus en plus vite vers le but qu'ils se sont assigné, tandis que les autres [resteraient] impuissants à retenir le passé au-delà de cette frange que la mémoire individuelle suffit à fixer [...] » (DERRIDA, 1967b, p. 187, grifo nosso).

Por um lado, a formulação de Lévi-Strauss supõe uma espécie de resto, de remanescente da concepção cristã do tempo - mesmo se laicizado: as sociedades com escrita progridem para o fim que elas - agora em lugar de Deus... - se atribuíram a si mesmas. Por outro lado, as consequências da sua ausência, para os povos "sem escrita", ostentam uma particularidade importante. Enquanto que a escrita inscreveria — nesta descrição — um sentido linear e irreversível daquilo que, ali, se refere ao "progresso" das sociedades que a conhecem, às sociedades ditas "sem escrita" ficaria reservada uma outra caraterização do tempo, marcada numa certa "flutuação" e "falta da origem". Elas, diz-nos Lévi-Strauss:

[...] resteraient prisonniers d'une histoire fluctuante à laquelle manquerait toujours une origine et la conscience durable d'un projet. Pourtant, rien de ce que nous savons de l'écriture et de son rôle dans l'évolution ne justifie une telle conception (DERRIDA, 1967b, p. 187).

Ora, aquilo a que Lévi-Strauss tende a recusar-se é reconhecer, nos avanços permitidos pela escrita - enquanto tecnologia de notação linear - um avanço civilizacional correspondente. Com efeito, é dele a afirmação: "se a minha hipótese for exacta, é preciso admitir que a função primária da comunicação escrita é a de facilitar a escravização"” (DERRIDA, 1967b, p. 190, tradução nossa). E um pouco mais adiante, ainda em Tristes tropiques - sempre citado por Jacques Derrida:

Si l'écriture n'a pas suffi à consolider les connaissances, elle était peut-être indispensable pour affermir les dominations. Regardons plus près de nous: l'action systématique des États européens en faveur de l'instruction obligatoire, qui se développe au cours du XIXème siècle va de pair avec l'extension du service militaire et la prolétarisation (DERRIDA, 1967b, p. 191-192).

Conclusão de Lévi-Strauss: "La lutte contre l'analphabétisme se confond ainsi avec le renforcement du contrôle des citoyens par le Pouvoir. Car il faut que tous sachent lire pour que ce dernier puisse dire : nul n'est censé ignorer la loi” (DERRIDA, 1967b, p. 192). 
Comentário de Jacques Derrida: se, por um lado, "esta proposição só tem sentido" na condição de "que se não leve, de forma nenhuma, em conta a ideia e o projeto da ciência, isto é, da verdade como transmissibilidade, por direito, infinita" (DERRIDA, 1967b, p. 187, tradução nossa) - posto que a ciência "só tem possibilidade com a escrita" (DERRIDA, 1967b, p. 187, tradução nossa)... - tal implicaria, por outro lado, que se renunciasse a reconhecer, ao seu próprio discurso, a qualidade de científico: "Cette dernière position ne manquerait pas de force, mais elle ne peut faire valoir cette force et sa cohérence qu'en renonçant elle-même à se donner pour un discours scientifique” (DERRIDA, 1967b, p. 188).

Pois embora, por um lado: “On sait depuis longtemps que le pouvoir de l'écriture aux mains d'un petit nombre, d'une caste ou d'une classe, a toujours été contemporain de la hiérarchisation, nous dirons de la différance politique [...]" (DERRIDA, 1967b, p. 190, grifo do autor).

Trata-se, nessa différance política, nessa hierarquização interna do coletivo, de um "fenômeno [que] ocorre no limiar da sedentarização" (DERRIDA, 1967b, p. 190, tradução nossa). Ou ainda: que tem lugar desde que a vida humana se organiza em sociedade. Desde, portanto, "quando a níveis muito heterogéneos de organização e de complexidade, é possível diferir a presença, quer dizer o dispêndio ou o consumo, e organizar a produção, quer dizer, a reserva em geral" (DERRIDA, 1967b, 190, grifos do autor, tradução nossa). É também preciso que se note, por outro lado, que

Dans ce texte, Lévi-Strauss ne fait aucune différence entre hiérarchisation et domination, entre autorité politique et exploitation. La note qui commande ces réflexions est celle d'un anarchisme confondant délibérément la loi et l'oppression (DERRIDA, 1967b, p. 190).

Anarquismo em que sentido? No de que "a ideia de lei e direito positivo, que é difícil de pensar na sua formalidade, naquela formalidade que se estima que ninguém a deve desconhecer antes da escrita, é determinada por Lévi-Strauss como coerção e escravização" (DERRIDA, 1967b, p. 190, tradução nossa). Que implicações teria essa espécie de atalho ou curto-circuito, esse anarquismo teórico de Lévi-Strauss, que o leva a confundir lei e opressão? Se o seu alinhamento da alfabetização, na instrução escolar obrigatória, com, não apenas a extensão do serviço militar obrigatório, mas também a proletarização não carecesse de demonstração seria, então, preciso aceitar aqui, com a mesma ênfase, as implicações do seu reverso pré-alfabético:

Si on l'en déduit néanmoins, comme c'est ici le cas, il faut aussitôt conclure que la nonexploitation, la liberté, etc., « vont de pair » (pour utiliser ce concept si équivoque) avec l'analphabétisme et le caractère non obligatoire du service militaire, de l'instruction publique ou de la loi en général (DERRIDA, 1967b, p. 190). 
Daí a sua conclusão, a respeito de Lévi-Strauss: "Présence à soi, proximité transparente dans le face-à-face des visages et l'immédiate portée de voix, cette détermination de l'authenticité sociale est donc classique : [...]" (DERRIDA, 1967b, p. 200).

Pois que ela é, na sua inspiração:

[...] rousseauiste mais déjà héritière du platonisme, elle communique, rappelons-le, avec la protestation anarchiste et libertaire contre la Loi, les Pouvoirs et l'État en général avec le rêve aussi des socialismes utopiques du XIXème siècle, très précisément avec celui du fouriérisme (DERRIDA, 1967b, p. 200).

Como pensar, então, este conceito de escrita que se diria poder opor-se, a dada altura, à "descoberta do outro", segundo Mia Couto? Seria possível observar, historicamente, o seu funcionamento, em conjugação com esta concepção teológica do signo, aqui abordada por Derrida?

\section{Escrita e "racismo": "a arrogância de um único saber"...}

É Michel de Certeau quem, logo na abertura do capítulo V do seu L'écriture de l'histoire — intitulado "Ethnographie: l'oralité, ou l'espace de l'autre: Léry" — nos chama a atenção para o fato de Lévi-Strauss haver considerado a Histoire d'un voyage faict en la terre du Brésil, publicada em 1578, da autoria do calvinista Jean de Léry, como um exemplo, avant la lettre, do "breviário do etnólogo" (CERTEAU, 1975, p. 249). Para Lévi-Strauss, na sua Histoire et etnologie:

L'ethnologie s'intéresse surtout à ce qui n'est pas écrit, non pas tant parce que les peuples qu'il étudie sont incapables d'écrire, que parce que ce à quoi il s'intéresse est différent de tout ce que les hommes songent habituellement à fixer sur la pierre ou sur le papier (DERRIDA, 1967b, p. 187).

A reserva em relação à escrita pressupunha, em Tristes tropiques, a sua coimplicação com uma certa inautenticidade das sociedades que a haviam adotado. Ela seria correlata do que nelas se inscreveria, então, do diferimento do sujeito (e da voz) - enquanto lugar(es) da presença a si do sentido; lembremo-nos aqui da leitura do Fedro, de Platão, por Jacques Derrida, em "La pharmacie de Platon": "a escrita é parricida" (DERRIDA, 1972, p. 189, tradução nossa), atentatória contra a origem ou a paternidade do sentido — no plano da relação ético-política:

Nous n'entendons pas nous livrer au paradoxe, et définir de façon négative l'immense révolution introduite par l'invention de l'écriture. Mais il est indispensable de se rendre compte qu'elle a retiré à l'humanité quelque chose d'essentiel, en même temps qu'elle lui apportait tant de bienfaits (DERRIDA, 1967b, p. 198). 
Que nos traz, então, Michel de Certeau? O que ele começa por sublinhar é o sentido do quanto a obra de Léry implicaria de uma certa "modernidade":

Du moins se manifeste ainsi l'une des règles du système qui s'est constitué comme « occidental » et «moderne » : l'opération scripturaire, qui produit, préserve, cultive des « vérités » non-périssables, s'articule sur une rumeur de paroles évanouis aussitôt qu'énoncées, donc perdues à jamais (CERTEAU, 1975, p. 249).

Fugindo de França para Genebra e viajando, depois, para o Brasil, Léry vem a estar, durante três meses, em 1556, entre os índios tupinambás, da zona litoral do Rio de Janeiro, para onde fora, a mando de Calvino, com o intuito de ali fundar um "Refúgio" calvinista. O livro, publicado cerca de vinte anos depois - em 1578 - aparece, por um lado, como uma crônica dessa viagem. Mas vem a ser tido, por outro lado - graças às abundantes descrições das suas observações dos índios - como obra de um inadvertido percursor do que virá a ser a observação etnológica. É diante das suas descrições que Michel de Certeau nos dirá: "L'élément décisif est ici la possession ou la privation d'un instrument capable à la fois de « retenir les choses en leur pureté » (Léry le dit plus loin) et de s'entendre « jusqu'au bout du monde »" (CERTEAU, 1975, p. 254).

Ora, "um outro funcionamento da escrita e da palavra" (CERTEAU, 1975, p. 247) se liga a esta operação escriturária: "no final desta investigação, neste seu ir e vir, ele produziu o Selvagem" (CERTEAU, 1975, p. 250, grifo nosso, tradução nossa). Que efeitos foram então os seus, sobre os saberes subjugados da cultura índia, tal como eles se deixam representar no livro?

En combinant le pouvoir de retenir le passé (alors que la «fable» sauvage oublie et perd l'origine) et celui de franchir indéfiniment da distance (alors que la « voix » sauvage este limitée au cercle évanouissant de son audition), l'écriture fait l'histoire (CERTEAU, 1975, p. 254).

O que significa, aqui, dizer que "a escrita faz a história"? Em que medida a faria ela? Por um lado, no sentido em que, tal como nota Jacques Derrida, a ciência encontra a sua possibilidade na escrita... Ou na possibilidade que ela nos traz de reprodução/transmissão infinita da verdade. O que diz de Certeau? 'D’un côté, elle accumule, elle stocke les « secrets » de par deçà, elle ne perd rien, elle les conserves intacts. Elle est archive. De l'autre elle « déclare », elle avance « jusqu'au bout du monde" [...] (CERTEAU, 1975, p. 254).

Se a escrita faz a história, é, portanto, não apenas porque constitui condição necessária do discurso historiográfico, enquanto transmissão de uma origem inalterada, mas também porque participa, associada ao cristianismo, dos "descobrimentos". O que supõe já toda a dificuldade da neutralidade do discurso historiográfico. Posto que, ao mesmo tempo que produz o selvagem ela produz, também, em seu lugar, a sua ausência da história: a sua retirada do discurso como 
história. O vazio, em suma, deixado pela sua ausência, entendida como mediação necessária ao retorno a si do Ocidente. Assim, a escrita: "Elle mue le voyage en un cycle. Elle ramène de làbas un objet littéraire, le sauvage, que permet de revenir vers le point de départ. Le récit produit un retour de soi à soi par la médiation de l'autre "(CERTEAU, 1975, p. 250).

O que essa operação escriturária produz é, portanto, um outro como troféu ou captura. Mas um outro que, enquanto objeto literário, corresponde, no entanto, ao buraco ou ao poço, ao furo da ausência — ou destituição — do seu discurso:

Aussi, dans l'écrin du récit, la parole sauvage fait figure d'un bijou absent. [...] Ce qui est un trou dans le temps, c'est la absence de sens. Le chant [des indiens] scande ici heu, heuaüre, ou plus loin, Hé, hua, hua, comme une voix fais re re, ou tralala (CERTEAU, 1975, p. 250-251).

Certeau refere-se aqui aos indecifráveis sons de um canto dos índios tupinambás reunidos em assembleia, tal como os descreve Léry. Não há, portanto, retorno a si - não há, em suma, presença a si... - sem esta produção do outro como ausência. Sem esta ausência do que, aqui, suporia, na sua opacidade, uma determinada recusa ao/do sentido. O que a "operação escriturária" moderna produziria seria, portanto, esta espécie de foraclusão do sentido no lugar do outro: esta isenção ou exclusão da alteridade. De facto: "nada dele [desse canto] se pode [afinal] transmitir, relatar ou conservar" (CERTEAU, 1975, p. 251, tradução nossa). E mesmo quando Jean de Léry se decide a servir-se de um intérprete, é ainda de um sentido projetivo que — aí interposto à escuta da fala nativa — se vem a tratar. Um sentido obliterador da alteridade. Os "descobrimentos" abrem, na modernidade colonial, para a produção de si mediante a expulsão do outro, enquanto discurso. Para a sua produção como Selvagem, em suma:

Alors s'effectue, avec ce passage au sens, la tâche qui transforme la ballade en produit utilisable. De ces voix, l'habile truchement retire le récit d'un déluge initial « qui est, note Léry, ce qu'ils tiennent entre eux plus approchant de l'Écriture sainte » (CERTEAU, 1975, p. 251).

A lógica desta operação escriturária é portanto, também, a da produção do regresso a si de uma Europa cindida, nessa altura, pelos movimentos da reforma. Esse regresso faz-se pelo estabelecimento do outro como exterioridade - uma exterioridade que funcionaria, assim, como (re)constitutiva de si, na sua unidade: '“[...] retour à l'Occident et à l'écriture, auxquels le cadeau de cette confirmation est rapporté des lointains rivages tupis; retour au texte chrétien et français par les soins conjugués de l'exégète et du voyageur" (CERTEAU, 1975, p. 251).

Assim, se, por um lado: "Entre « eux » et « nous », il y a la différence de cette écriture « soit sainte soit profane » qui met immédiatement en cause un rapport de pouvoir. [...] Les Occidentaux ont l'avantage [disent les indiens, selon Léry...]" (CERTEAU, 1975, p. 253). 
É porque, por outro lado, o dom da escrita é "contra-assinado" pelo absoluto, pela divindade da qual provém:

Ils [les indiens] le créditent d'être l'un des « dons singuliers que les hommes de par deçà ont reçu de Dieu » : leur pouvoir culturel est contresigné de l'absolut; ce n'est pas un fait, mais un droit, l'effect d'une élection, un héritage divin (CERTEAU, 1975, p. 253).

De fato, a inscrição desta articulação binária, entre a fala do outro e uma escrita aqui encarada como testemunho da presença de Deus — ou dom e extensão do seu poder, "deixa intacto o poder colonizador" (CERTEAU, 1975, p. 254):

Le pouvoir que son expansionnisme laisse intact est, en son principe, colonisateur. Il s'étend sans être changé. Il est tautologique, également immunisé contre l'altérité qui pourrait le transformer et contre celle qui pourrait lui résister (CERTEAU, 1975, p. 254, grifo nosso).

Compreende-se, finalmente, a esta luz, que:

Le sauvage devient la parole insensée qui ravit le discours occidental, mais qui, à cause de cela même, fait écrire indéfiniment la science productrice de sens et d'objets. $L a$ place de l'autre, qu'il représente, est donc doublement fable : [...] (CERTEAU, 1975, 283, grifo do autor).

Por quê "duplamente"? Por um lado, porque "fari [verbo de que vem, etimologicamente, a palavra "fábula", é] o ato de falar que não tem sujeito nomeável" (CERTEAU, 1975, p. 283). Por outro lado, porque "fábula" designa "uma ficção a traduzir em termos de saber" (CERTEAU, 1975, p. 283). E com efeito, em "Desemparedar o pensamento", um dos ensaios de $O$ universo num grão de areia, Mia Couto não deixava de observar: "Houve, em suma, um processo de esquecimento e anulação das histórias da História. Nós praticamos sem o saber uma espécie de historicídio. Este historicídio não é apenas o resultado de uma arrogância eurocêntrica" (COUTO, 2019, 184).

Esse historicídio está ligado, na cultura que, entretanto, se foi globalizando, a uma concepção "mecanicista e utilitária do nosso pensamento" (COUTO, 2019, p. 184), que se afirma em detrimento da sua concepção "relacional" (COUTO, 2019, p. 181), sustentada na tradição oral. E isso afeta a nossa ideia da escrita:

Essa tendência redutora faz com que a própria escrita seja entendida como uma ferramenta. E mais do que isso, como uma fronteira. $\mathrm{O}$ aparecimento da escrita funda uma linha separadora da nossa identidade e identidade dos outros, os que habitam a oralidade (COUTO, 2019, p. 185). 
Além disso, essa separação acabou por reforçar, “a posteriori [uma] classificação discriminatória das culturas e das religiões" (COUTO, 2019, p. 185): “O advento do monoteísmo sofisticou este critério, que exclui da razão e da verdade os que, por terem outras crenças, são olhados como não tendo crença nenhuma. Um Deus que se quer único escreve ou manda que se escreva" (COUTO, 2019, p. 185).

Essa relação entre escrita e religião haveria de reforçar os seus poderes simbólicos: "a palavra de Deus passou a estar no livro. A dessacralização da terra e da natureza deslocou o sagrado para a prova da escrita. [... Ora] Com a escrita nasce a História” (COUTO, 2019, p. 186). Pensamo-la, hoje:

Como se houvesse um único pensamento, com uma única génese e com um único tipo de processos. [...] Falamos como se o pensamento tivesse apenas uma única história, como se esta longa narrativa da produção de ideias tivesse uma única dimensão (COUTO, 2019, p. 182).

Gesto de denúncia idêntico ao que encontramos em "Línguas que não sabemos que sabíamos", logo na abertura de E se Obama fosse africano? e outras interinvenções, onde Mia Couto sublinhava que "os sistemas de pensamento da ruralidade africana não são facilmente redutíveis às lógicas dominantes da Europa" (COUTO, 2009a, p. 22). E afirmava, um pouco mais adiante: "Esta diversidade de pensamento sugere que talvez seja necessário assaltar um último reduto de racismo que é a arrogância de um único saber e a incapacidade de estar disponível para filosofias que nos chegam das nações empobrecidas" (COUTO, 2009a, p. 23).

De fato, para o autor:

O que aconteceu na história da nossa espécie sucede também na narrativa individual de cada um de nós. A criança que aprende a ler e a escrever separa-se da sua própria préhistória. A infância — que é o tempo em que habitamos a oralidade — é tida como um estado de menoridade, de insuficiência e de carência (COUTO, 2019, p. 186).

Daí a necessidade de - a essa pré-história, que nos é constitutiva... - a escutarmos e acolhermos no que dela se inscreve, não apenas na nossa escrita, mas também na nossa leitura...

\section{Referências}

ADORNO, Theodor. Esprit du monde et histoire de la nature: digression sur Hegel. Dialectique négative. Paris: Payot, 2001.

AGAMBEN, Giorgio. Temps et histoire: critique de l'instant et du continu. Enfance et histoire. Paris: Payot \& Rivages, 2000.

BHABHA, Homi K. The postcolonial and the postmodern: the question of agency. The Location of Culture. New York: Routledge, 1994. 
CERTEAU, Michel de. Ethnographie: l'oralité, ou l'espace de l'autre: Léry. L'écriture de l'histoire. Paris: Gallimard, 1975.

COUTO, Mia. Línguas que não sabemos que sabíamos. In: Ese Obama fosse africano? E outras interinvenções. Lisboa: Caminho, 2009a.

. Quebrar armadilhas. In: . E se Obama fosse africano? E outras interinvenções. Lisboa: Caminho, 2009b.

Encontros e encantos: Guimarães Rosa. In: . E se Obama fosse africano? E outras interinvenções. Lisboa: Caminho, 2009c.

. Luso-afonias: a lusofonia entre viagens e crimes. In: . E se Obama fosse africano? E outras interinvenções. Lisboa: Caminho, 2009d.

. Desemparedar o pensamento. O universo num grão de areia. Lisboa: Caminho, 2019. DERRIDA, Jacques. La fin du livre et le commencement de l'écriture. De la grammatologie. Paris: Minuit, 1967a.

. La Violence de la lettre: de Lévi-Strauss à Rousseau. De la grammatologie. Paris: Minuit, 1967b.

. La Pharmacie de Platon. La Dissémination. Paris: Seuil, 1972.

. My chances/Mes chances. A rendezvous with some epicurean stereophonies. Psyché: Inventions of the Other. Stanford UP, 2007. v. I.

FOUCAULT, Michel. Two lectures. Power/knowledge: selected interviews and other writings: 1972-1977. New York: Pantheon Books, 1980.

. L'Herméneutique du sujet: cours aux Collège de France: 1981-1982. Paris: Seuil/ Gallimard, 2001a.

Nietzsche, la généalogie, l'histoire. Dits et écrits de Michel Foucault (1954-1988). Paris: Gallimard, 2001b. v. I.

LÖWITH, Karl. Hegel. O sentido da história. Lisboa: Edições 70, 1990.

\section{Minicurrículo}

José Paulo Cruz Pereira nasceu na ilha de Moçambique. Licenciou-se em Línguas e Literaturas Modernas pela Universidade Clássica de Lisboa, onde defendeu, em 1996, tese de mestrado em Literatura Comparada, mais tarde publicada com o título Uma cartografia transtornada: a Guernica de Carlos de Oliveira. Doutorou-se, em 2004, em Literatura Comparada pela Universidade do Algarve, onde leciona Literaturas Estrangeiras de Língua Portuguesa II e Comunicação na Contemporaneidade, e tem ensinado em diversos mestrados - nas áreas dos Estudos Pós-coloniais e dos Estudos Culturais, as quais atualmente investiga como membro do Grupo 7 do Centro de Literaturas e Culturas Lusófonas e Europeias (CLEPUL). 